\title{
Pyrolysis of Lemon Peel Waste in a Fixed-bed Reactor and Characterization of Innovative Pyrolytic Products
}

\section{Samira ABIDI}

Centre de Recherches et Technologies de l'Energie

Aïda Ben Hassen Trabelsi ( $\sim$ aidabenhassen@yahoo.fr)

CRTEn: Centre de Recherches et Technologies de l'Energie https://orcid.org/0000-0002-8473-7119 Nourhène Boudhrioua Mihoubi

Universite de la Manouba Institut Superieure de Biotechnologie de Sidi Thabet

\section{Research Article}

Keywords: lemon peels waste, pyrolysis, fixed bed reactor, biofuels, antioxidants

Posted Date: August 14th, 2021

DOI: https://doi.org/10.21203/rs.3.rs-656531/v1

License: (1) (1) This work is licensed under a Creative Commons Attribution 4.0 International License.

Read Full License 
3 Samira Abidi ${ }^{1,2,3}$, Aïda Ben Hassen Trabelsi $1^{*}$, Nourhene Boudhrioua Mihoubi ${ }^{3}$

$4 \quad{ }^{1}$ Research and Technology Center of Energy - CRTEn, Borj-Cedria, Technopark,

5 B.P N95 2050 -Hammam Lif - Tunisia.

$6 \quad{ }^{2}$ Faculty of Sciences of Bizerte, University of Carthage, 7021 Bizerte, Tunisia.

$7 \quad{ }^{3}$ University of Manouba, Higher Institute of Biotechnology Sidi Thabet, Laboratory of

8 Alimentation, Physiopathology and Biomolecules, LR17ES03, BioTechPole Sidi

9 Thabet, SidiThabet, 2020, Tunisia.

\section{Abstract}

The pyrolysis of LPW was carried out in a laboratory fixed-bed reactor at final temperature of $300^{\circ} \mathrm{C}, 400^{\circ} \mathrm{C}$ and $500^{\circ} \mathrm{C}$ with an incremental heating rate of $10^{\circ} \mathrm{C} / \mathrm{min}$, under $\mathrm{N}_{2}$ atmosphere. The maximum yields of bio-oil, biochar and gas were $16.66 \mathrm{wt} . \%$ (at $\left.400^{\circ} \mathrm{C}\right), 66.89$ wt. $\%\left(300^{\circ} \mathrm{C}\right)$ and $54.6 \mathrm{wt} . \%\left(500^{\circ} \mathrm{C}\right)$, respectively. The recovered biochar FTIR characterization reveals that it is a promising precursor to produce carbon materials, biofertilizer and for solid fuel applications. The bio-oil chemical characterization (GC-MS and FTIR analyzes) shows its richness with innovative compounds such as squalene, d-limonene, B-Sitosterol and phenol, suitable for applications agriculture, biochemical and pharmaceutical industries. The pyrolytic oil presents also good properties, suitable for its use as an engine fuel or as a potential source for synthetic fuels. The recovered pyrolytic gas has a maximum calorific value around $12 \mathrm{MJ} / \mathrm{kg}$ with an average composition of $\mathrm{CO}$ (up to $75.87 \mathrm{vol} . \%$ ), of $\mathrm{CH}_{4}$ (up to 5.25 vol.\%) and of $\mathrm{C}_{\mathrm{n}} \mathrm{H}_{\mathrm{m}}$ (up to 1.48 vol.\%). The results could be applied by citrus 
25 farmers and agri-food industrials for large scale application to ensure a sustainable 26 waste management of their citrus by-products and to guarantee economic benefits.

27

28 Keywords: lemon peels waste; pyrolysis; fixed bed reactor; biofuels; antioxidants.

29

30 
The exploitation of new renewable resources to produce biofuels as a replacement for the use of the conventional derivates of petroleum has received an increasing global research interest. Global climate change associated with the extensive release of greenhouse gases (GHG) have raised concern about the application of fossilized hydrocarbons as the main energy source (Patsalou et al. 2019). In this context, the transformation of agro-industrial waste into renewable biofuels can reduce fossil fuel dependency, contribute to lower GHG emissions and considerably diminish the pollution associated to the unsafe disposal of agro-industrial residues (Mahato et al. 2020). Currently, the citrus processing industry generates a substantial waste stream in areas of important citrus production (Negro et al. 2018). Amongst the agro-industrial wastes, citrus waste is abundant feedstock, inexpensive raw materials and readily available for renewable energy production (Mahato et al. 2020). Citrus crops are highest abundant worldwide with yearly production of around 120 million tons of oranges, lemons, grapefruits and mandarins (Lopez-Velazquez et al. 2013). In Tunisia, citrus production is estimated to 560000 tons in 2018 , which represents $0.7 \%$ of the global citrus production. Several varieties are cultivated in Tunisia among which maltaise, lemon and mandarin are the most produced ones $(27 \%, 15 \%$ and $2.16 \%$ of the national citrus production, respectively) (GIFruits, 2018) It is estimated that $33 \%$ of the citrus harvest in the world is transformed into juice (Ahmad Taghizadeh-Alisaraei , Seyyed Hasan Hosseini, Barat Ghobadian 2016). As most of agro-industrial activities, the citrus conversion sector leads to the manufacturing of huge quantities of organic waste. It is estimated that $40-60 \%$ of the citrus are converted into organic waste: peels, pulp and 
industry (Sharma et al. 2018). Therefore, the suitable management of these organic residues constitutes a permanent concern for the citrus processing industry. Current management practices of CPW include first generation recycling methods, such as animal feed after drying, composting since they are very rich in sugar fibers (Siles López et al. 2010), disposal in landfills and anaerobic digestion (Patsalou et al. 2020) and for recovery of biologically active composites (such as phenolic acids and flavonoids pectin, fibers...etc) (M'hiri et al. 2015). But these conventional techniques of CPW processing are insufficient and induce many problems in terms of energy productivity and environmental consequences (Wei et al. 2017).

The chemical composition of CPW reveals a significant content of pectin in addition to cellulose, hemicellulose and lignin as major components (Alvarez et al. 2018). These lignocellulosic wastes could be considered as attractive feedstock to produce renewable fuels and innovative products (biofertilizers, bioactive molecules). Regarding the significant calorific power of CPW (around $17 \mathrm{MJ} / \mathrm{kg}$ dry basis), their direct use for energy transformation across combustion (Siles et al. 2016) or for offering energy vectors through thermochemical processes such gasification (Chiodo et al. 2017a) could be a solution for providing energy for citrus product transformation industry (Zema et al. 2018). Pyrolysis is the thermochemical process that, in the lack of oxygen, converts organic wastes into valuable products including solid char, liquids (hydrocarbons and water) and gaseous products. Few studies have been done on the pyrolysis of CPW; most of them have been performed on orange peel waste (Aguiar et al. 2008; Miranda et al. 2009; Morales et al. 2014; Volpe et al. 2015; Kim et al. 2015a; Alvarez et al. 2018) and mandarin peel waste (Adeniyi et al. 2019). Aguiar et al. ( 2008) while studying the 
they investigated the influence of pyrolysis temperature $\left(300,500\right.$ and $\left.600^{\circ} \mathrm{C}\right)$ and particle size $(300-800 \mathrm{~mm})$ on products yields, gas composition and biochar heating value. They denoted that the temperature of the pyrolysis is the parameter which exerts the most important influence on the products yields more than particle size. Miranda et al. (2009) carried out the pyrolysis of dry peels sweet orange (citrus sinensis) and highlighted that these wastes have a high potential for producing liquid fuel (around $53.1 \%$ of bio-oil) due to their volatile content $(78.9 \% \mathrm{w} / \mathrm{w})$ and their little ash content $(2.94 \% \mathrm{w} / \mathrm{w})$ with an average yields of biochar and gas around $21.1 \%$ and $25.8 \% \mathrm{w} / \mathrm{w}$, respectively. Morales et al. (2014) studied the solar pyrolysis of orange peel and reported a high bio-oil yield (around 77.64\%), a moderate biochar yield (20.93\%) and only little percentage of gas (around 1.43\%). Volpe et al. (2015) studied slow pyrolysis in a laboratory-scale fixed-bed reactor of dried citrus waste (lemon and orange peel) resulting from the citrus juice industry and reported that bio-oil yield varies between $36 \%$ and $39 \% \mathrm{w} / \mathrm{w}$ for a temperatures range of $400-650^{\circ} \mathrm{C}$; whereas the biochar yield was between $37.2 \%$ and $40.8 \% \mathrm{w} / \mathrm{w}$. Alvarez et al. (2018) performed the fast pyrolysis of orange waste and reported that bio-oil yield is close to $55 \mathrm{wt} . \%$ in the interval of temperature between 425 and $500^{\circ} \mathrm{C}$ and a moderate yield of biochar, varying from 27 to 33 wt.\%.

The previous studies of CPW pyrolysis focused essentially on the conversion of orange and mandarin peel wastes to produce biochar. Few studies were interested in the optimization of the pyrolysis of Lemon Peel Waste (LPW) (Patsalou et al. 2019) with a focus on all pyrolysis products (bio-oil, biochar and gas) and on their adequate and specific uses especially in nonconventional application using active biomolecules. Adeniyi et al. (2019) developed a steady state thermodynamic model for the pyrolysis 
of lemon peel tested at $500^{\circ} \mathrm{C}$ and atmospheric pressure. The authors reported that the lemon peels were the best for bio-oil production compared to other biomass peel waste. Thus, more information on the pyrolysis of LPW and on the optimal conditions of biooil, biochar and gas is still lacking and a deep investigation of end products characteristics of LPW pyrolysis is required. The principal objective of this paper is to explore, firstly, the pyrolysis of LPW into innovative pyrolytic products having potential applications not only in energy, biofertilizer and biofuel production but also in biochemical and pharmaceutical industries. It attempts to explore the consequence of pyrolysis final temperature on pyrolytic products yields and qualities and to evaluate the prospective application of each pyrolysis end product.

\section{Material and Methods}

\section{Preparation of the samples}

LPW used for this work were collected in March 2017, from a juice citrus factory in Cap Bon (Northern Tunisia). The fresh material was collected immediately after processing. The freshly processed LPW was slash into little pieces of an average area of $2 \mathrm{~cm}^{2}$ and were oven dried for $48 \mathrm{~h}$ at $60^{\circ} \mathrm{C}$ to diminish the moisture content until 10\% (Ghanem Romdhane et al. 2015). The dried LPW was ground in a mill and then sieved in order to obtain homogenous products with 2 to $4 \mathrm{~mm}$ particle sizes.

\section{Experimental setup and procedure}

The pyrolysis experiments of dried LPW were carried in April 2017 using a laboratory scale fixed-bed reactor at final temperatures of $300^{\circ} \mathrm{C}, 400^{\circ} \mathrm{C}$ and $500^{\circ} \mathrm{C}$, with a heating rate of $10^{\circ} \mathrm{C} / \mathrm{min}$ and under atmospheric pressure. The pyrolysis setup used in this work was report in details in (Ben Hassen Trabelsi et al. 2018) (Fig. 1). The pyrolysis experiments were conducted on a batch fixed-bed reactor heated with an electric 
furnace. The reactor is flushed with nitrogen to prevent oxygen introduction into the

128

129 reactor and to guarantee an inert medium for pyrolysis reactions and the reactor axial temperature is followed using a K-type thermocouple. The pyrolysis gases pass through a condensation system to collect bio-oil and non-condensable gases, separately.

Each experiment was conducted in duplicates, in order to confirm reproducibility and the obtained products yields mentioned are the average value of two equivalent runs. The end products were put in dark vials and stored at $4{ }^{\circ} \mathrm{C}$ for further analyzes. Pyrolysis products yields are determined by weighing the biochar and the bio-oil (Bensidhom et al. 2017) and by using the following equations (1), (2) and (3) :

$$
\text { Bio-oil yield wt. } \%=\frac{\text { bio-oil collected weight }}{\text { initial feedstock weight }} \times 100
$$

$$
\text { Biochar yield wt. } \%=\frac{\text { biochar collected weight }}{\text { initial feedstock weight }} \times 100
$$

Gas yield wt. $\%=100-($ biochar yield wt. $\%+$ bio - oil yield wt. \%)(3)

\section{Analytical methods}

\section{Proximate and ultimate analysis of LPW and biochar samples}

The moisture content of LPW samples was determined by the weight loss after drying at $105^{\circ} \mathrm{C}$ for 24 hours (AFNOR,2010). The volatile matter (VM) content of LPW samples was determined based on the mass loss after samples combustion at $900{ }^{\circ} \mathrm{C}$ for $4 \mathrm{~min}$ (AFNOR, 2010). Ash content was calculated by using the standard methods (AFNOR 2010). The fixed carbon (FC) amount was obtained according to (Volpe et al. 2015) as follows:

$$
\mathrm{FC}=100-(\mathrm{VM}+\mathrm{Ash})(\mathbf{4})
$$

Ultimate analysis $\mathrm{CHN}-\mathrm{O}$ was fulfilled using a $\mathrm{CHN}$ elemental analyzer (Perkin Elmer 2400 , country). The oxygen content was determined by difference. 
The High Heating Value (HHV) calculation was established based on the ultimate analysis data (CHN-O) using the following formula (Bensidhom et al. 2017):

$$
\mathrm{HHV}=-1.3675+0.3137 \times \mathrm{C}+0.7009 \times \mathrm{H}+0.00318 \times \mathrm{O}(\mathrm{MJ} / \mathrm{kg})(5)
$$

The determination of proximate and ultimate analyzes of LPW and produced biochar allows the evaluation of LPW suitability as feedstock for the pyrolysis and the estimation of their energetic potential.

\section{FTIR spectroscopy of LPW, biochar and bio-oil samples}

Fourier Transform Infrared (FTIR) spectroscopy analyzes were performed in order to find out the functional groups composition of raw material (LPW), bio-oil and biochar. FTIR analyzes will be useful for further determination of potential applications for molecules having bioactive functional groups. The FTIR spectra were registered on $\mathrm{KBr}$ pellets using a FTIR spectrometer (Perkin Elmer, FTIR 2000), in the spectral range of $400-4000 \mathrm{~cm}^{-1}$.

\section{Thermogravimetric analyzes of LPW}

Thermogravimetric (TGA-DTG) analyzes were conducted to investigate the thermal degradation behavior of LPW by following the mass loss with the temperature increase, using a TGA Thermogravimetric analyzer (SETSYS-1750) under Argon atmosphere in the temperature range between $30^{\circ} \mathrm{C}$ and $700^{\circ} \mathrm{C}$ and the heating rate of $10^{\circ} \mathrm{C} / \mathrm{min}$. The thermogravimetric analyzes (TG-DTG) of LPW are useful for the comprehension of the thermal behavior of LPW under heating in an inert medium and for the selection of end pyrolysis temperature.

\section{Gas chromatography-mass spectrometry of bio-oil}

Bio-oil samples were derivatized using bis (trimethylsilyl) tri fluoroacetamide (BSTFA) and pyridine, in order to produce trimethylsilylester derivatives. Around 10 
mg of the bio-oil sample was derivatized with $100 \mu \mathrm{L}$ of pyridine and $100 \mu \mathrm{L}$ of BSTFA. The solution was jumbled in a vortex and left to stand for $30 \mathrm{~min}$ at $70{ }^{\circ} \mathrm{C}$. The GC-MS analyzes of the produced bio-oil were performed using an Agilent 7890A GC equipped with an Agilent 5975C mass-selective detector (MSD). The capillary column was HP-5MS 5\% Phenyl Methyl Siloxof $30 \mathrm{~m}$ long, $0.25 \mathrm{~mm}$ internal diameter, and $0.25 \mu \mathrm{m}$ film thickness. The oven was programmed to hold at $70^{\circ} \mathrm{C}$ for $2 \mathrm{~min}$, then a ramp at $7^{\circ} \mathrm{C} / \mathrm{min}$ to $300^{\circ} \mathrm{C}$ and hold there for $10 \mathrm{~min}$. The injector temperature was set to $250^{\circ} \mathrm{C}$. The injector split ratio was set to $10: 1$ ratio. The carrier gas was helium ( $1 \mathrm{ml} / \mathrm{min})$. The identification of bio-oil compounds was performed according to the NIST database and by comparing to previously published mass spectra data.

GC-MS analyzes of studied bio-oils were conducted in order to explore the molecules group content recognized in literature as active or bioactive.

\section{Pyrolytic gas chemical composition determination}

The gas chemical composition and the calculated calorific content (Low heating value LHV) of the produced pyrolytic gas were determined by a gas analyzer (GEIT 3160 model, Belgium). Before analyzes, the gaseous mixture was purified in order to reduce tars and water (Ben Hassen Trabelsi et al. 2018).Results and Discussion

\subsection{Samples characterization}

Proximate analyzes

193 The proximate results of the LPW are set in Table 1. As it is shown, pre-dried LPW 194 sample has moisture content around 10.86\%. The drying pre-treatment (using open air and oven) was a fundamental step before pyrolysis, since the fresh LPW samples are very humid (moisture content around $78.1 \%$ by weight) and the pyrolysis process 
The pre-drying process is usually recommended before pyrolysis experiments in order to avoid additional heat to remove the moisture from biomass and to reduce pyrolysis products (mainly bio-oil) moisture content.

The volatile matter (VM) content of LPW was about $80 \%$. This VM value was in the same range of those obtained for other LPW (Table 1) (77.22\% (Volpe et al. 2015); 87.16 \%(Pathak et al. 2017) and for other CPW (74.3\% (Kim et al. 2015a); 57.5\% (Chiodo et al. 2017b)). The high VM content of studied LPW sample reveals its suitability as raw material for pyrolysis process since biomass with high VM is easily devolatilized and also produces less char. The LPW ash content is around $5.37 \%$.

\section{Ultimate analyzes}

Besides, the studied LPW showed high amounts of carbon (46.1\%), of hydrogen (7.36\%), of nitrogen $(1.02 \%)$ and of oxygen $(51.52 \%)$ (Table 1). The high content of organic matter (as carbon and hydrogen) makes LPW suitable for thermal conversion (Fernandez et al. 2016).

The results shown in Table 1 are in agreement with those of other investigators: $40.33 \%$ C, $5.96 \% \mathrm{H}, 1.27 \% \mathrm{~N}$ and $52.25 \%$ O, reported by (Chiodo et al. 2017a) for Lemon Peel; $45.04 \% \mathrm{C}, 5.78 \% \mathrm{H}, 1.75 \% \mathrm{~N}$ and $47.43 \% \mathrm{O}$, reported by (Arni 2017) for in sugarcane bagass.

The calculated HHV of LPW is around $18 \mathrm{MJ} / \mathrm{kg}$. This HHV value is close to those obtained for other lignocellulosic biomasses reported in the literature, such as surgarcane bagasse (18.17 MJ/kg) (Arni 2017), rice husk (14.69 MJ/kg) (Yin 2011) and grape bagasse (22.06 MJ/kg) (Demiral and Asl 2011).

\section{LPW Thermal behavior}


221 Figure 2 shows the thermal behavior of LPW by simultaneous TG (mass loss) and DTG

222 (derivative thermogravimetric) evolution profiles as a function of temperature. Three stages were distinguished for the principal thermal processes up to $700^{\circ} \mathrm{C}$. The first stage starts at $26^{\circ} \mathrm{C}$ and ends at $133^{\circ} \mathrm{C}$ with a mass loss about $12.38 \%$ on account of the removal of moisture and very light volatile components from biomass (Miranda et al. 2009; Varma and Mondal 2016; Zaafouri et al. 2016). The second stage starts at $134^{\circ} \mathrm{C}$ and finishes at $407^{\circ} \mathrm{C}$ with a global mass loss of $50.8 \%$. It should be noted that this stage is mainly characterized by the degradation of pectin, hemicelluloses and cellulose (Lopez-Velazquez et al. 2013). In this stage, the maximum degradation temperature of pectin is at $162^{\circ} \mathrm{C}$ with a mass loss of $2.18 \%$, that of hemicelluloses is at $230^{\circ} \mathrm{C}$ with a mass loss of $26.63 \%$, and that for cellulose is at $330^{\circ} \mathrm{C}$ with a mass loss of $19.08 \%$. This interval was considered as an active pyrolysis stage (Varma and Mondal 2016) . Aguilar et al. (2012) while investigating the thermal comportment of fresh lemon, reported that the decomposition peaks found are $160^{\circ} \mathrm{C}(9 \%), 235^{\circ} \mathrm{C}(22 \%)$, and $328^{\circ} \mathrm{C}$ $(8.3 \%)$ and correspond in fresh lemon to pectin, hemicellulose, and cellulose, respectively. The third stage, from $408^{\circ} \mathrm{C}$ to $700^{\circ} \mathrm{C}$, is assigned to the presence of lignins in the biomass sample with a mass loss of $4 \%$ at temperature maximal of $462^{\circ} \mathrm{C}$. The last stage is referred as passive pyrolysis (Miranda et al. 2009; Varma and Mondal 2016; Chiodo et al. 2017b). Its decomposition go down slowly under a wide range of temperature from ambient to $700{ }^{\circ} \mathrm{C}$ (Dhyani and Bhaskar 2017). The thermal decomposition of hemicelluloses, cellulose and lignins is well studied in the literature and it is specified that their decomposition temperature ranges are $210-325,310-400$ and $160-900^{\circ} \mathrm{C}$, respectively) (Boluda-Aguilar and López-Gómez 2012; Aboulkas et al. 
LPW FTIR spectra is presented in Figure 3. The wide band in the energy zone (3100$3500 \mathrm{~cm}^{-1}$ ) is assigned to $\mathrm{O}-\mathrm{H}$ stretching vibrations of carbohydrates and lignins, in addition to the symmetric and asymmetric stretching vibrations associated with $\mathrm{H}_{2} \mathrm{O}$ molecules (Yin 2011; Lopez-Velazquez et al. 2013; Bensidhom et al. 2017). Stretching vibrations at 1743 are due to $\mathrm{C}=\mathrm{O}$ and $\mathrm{C}-\mathrm{O}$ bonds of the acetyl ester units present in hemicelluloses. The intense band at $1065 \mathrm{~cm}^{-1}$ corresponds to the link $\mathrm{C}-\mathrm{O}-\mathrm{H}$ or C-O-R (alcohols or esters) while the distinctive band at $2897 \mathrm{~cm}^{-1}$ is related to the presence of $\mathrm{C}-\mathrm{H}$ stretching vibration together with bending vibrations around $1430 \mathrm{~cm}^{-1}$ of aliphatic chains $\left(\mathrm{CH}_{2}\right.$ and $\left.\mathrm{CH}_{3}\right)$ forming the basic structure of these lingo-cellulosic materials (Boluda-Aguilar et al. 2010; Lopez-Velazquez et al. 2013). The band shown at around $622 \mathrm{~cm}^{-1}$ is attributed to $\mathrm{CH}$ aromatic stretching vibrations and $\mathrm{CH}_{2}$ deformation vibration (Anukam et al. 2016; Zaafouri et al. 2016). The aliphatic and oxygenated functional groups contents of raw LPW emphasize their potential use as feedstock for pyrolysis process.

\section{Pyrolysis products yields}

LPW pyrolysis products distribution is given in Figure 4. Biochar yield decreased from 66.9 wt. $\%$ to 31.5 wt. $\%$ when the temperature increased from 300 to $500^{\circ} \mathrm{C}$ while the pyrolytic gas yield increased from 26.9 to $54.6 \%$ when temperature rose from 300 to $500^{\circ} \mathrm{C}$. The bio-oil yield showed a maximum value (around $16.6 \%$ ) at $400^{\circ} \mathrm{C}$. The biooil yields reduction at high temperature is mainly due to secondary reactions (rupture and rearrangement) of the pyrolysis vapors, which participates to the increase of the gaseous product (Primaz et al. 2018). At $500^{\circ} \mathrm{C}$, the yield of condensable and noncondensable products dropped by around $68.53 \mathrm{wt} . \%$. This reaction is compatible with 
269 TGA (Fig. 2), where weight loss at $500^{\circ} \mathrm{C}$ was observed. The yield of bio-oil acquired 270 in this work is slightly lower than that indicated for the pyrolysis of LPW or similar

271 citrus waste, which range from 35 to 53\% by weight (Miranda et al. 2009; Volpe et al. 272 2015; Kim et al. 2015a; Wang et al. 2018). The decrease of biochar yield with 273 temperature increase could be due either to the primary decomposition of the biomass at higher temperatures or through secondary decomposition of the char residue in the form of dehydrogenation and dehydration of hydroxyl groups reaction (Aboulkas et al. 2017). This result is comparative to those reported by Volpe et al. (2015), who investigated the slow pyrolysis of the lemon peel juice industries in a fixed-bed pyrolysis reactor after drying, where the biofuel yield decreased from $55.3 \%$ to $38.2 \%$, respectively, at from $300^{\circ} \mathrm{C}$. It is believed that the increase of pyrolytic gas proportion is mainly due to the secondary cracking of the pyrolysis vapors at higher temperatures. However, secondary decomposition of char at higher temperatures can give non-condensable gaseous products.

\section{Characterization of pyrolysis products}

\section{Biochar characterization}

Proximate and ultimate analyzes in Table 2 show that by increasing the severity of the treatment, the solid residues have a moisture content below equilibrium and that the volatile mass decreases rapidly (from $75 \%$ to $68 \%$ ). The obtained biochar fixed carbon content is about $18.34 \% \mathrm{C}$ (at $300^{\circ} \mathrm{C}$ ) and $31.88 \% \mathrm{C}$ (at $500{ }^{\circ} \mathrm{C}$ ). By increasing pyrolysis temperature, most of the oxygenated compounds in the biological reservoir are lost $\left(\mathrm{O} \%=41.68 \%\right.$ at $300^{\circ} \mathrm{C}$ and $\mathrm{O} \%=21.36 \%$ at $\left.500{ }^{\circ} \mathrm{C}\right)$. Besides, carbon content increases from $51.41 \%$ at $300{ }^{\circ} \mathrm{C}$ to $72.29 \%$ at $500{ }^{\circ} \mathrm{C}$, which positively affects the char calorific values, increasing from 19.88 at $300{ }^{\circ} \mathrm{C}$ to $24.42 \mathrm{MJkg}^{-1}$ at $500{ }^{\circ} \mathrm{C}$. Similar 
HHV's were obtained for other chars from the pyrolysis of orange peel or citrus wastes

294

295

296

297

298

299

300

301

302

303

304

305

306

307

308

309

310

311

312

313

314

315

316

at temperatures between 300 and $600^{\circ} \mathrm{C}$ (Alvarez et al. 2018). The hydrogen content of the studied chars decreases with the temperature increase of the pyrolysis. Biochar product obtained at different temperatures shows also less amount of fixed carbon and hydrogen than raw LPW which is attributed to lignocelluloses volatilization (Zaafouri et al. 2016).

FTIR spectra of biochar obtained from LPW pyrolysis is shown in Figure 5(a). The peak assignments description is provided in Table 3. Remarkably, the intensity of the hydroxyl groups, of the C-H stretching associated to aliphatic com- pounds and the carbonyl band $\mathrm{C}=\mathrm{O}$ decreased with rising temperature. The $\mathrm{O}-\mathrm{H}$ stretching vibration at $3600-3100 \mathrm{~cm}^{-1}$ in the FTIR spectra of the biochar sharply decreased after pyrolysis, probably due to the further dehydration of the LPW (release of residual water) (Aboulkas et al. 2017). Compared to raw LPW, pyrolysis at $300^{\circ} \mathrm{C}, 400^{\circ} \mathrm{C}$ and $500^{\circ} \mathrm{C}$ resulted in decrease of the absorption intensity of O-H (3394-3309 $\left.\mathrm{cm}^{-1}\right)$ and aliphatic C-H $\left(2922 \mathrm{~cm}^{-1}\right)$ functional groups, mainly due to dehydration of residual cellulose and/or hemicellulose in LPW sample. Thus this result is alike to the studies conducted by Volpe (Volpe et al. 2017) and Wang (Wang et al. 2018) on residual biochars produced from citrus waste and rice husk, respectively. At higher temperatures the less intense signal in FTIR is related to aromatics undergoing condensation reactions and forming more rigid structures closer to graphite (Volpe et al. 2017). At $400^{\circ} \mathrm{C}$, the distinctive absorption peaks at $3400 \mathrm{~cm}^{-1}, 2920 \mathrm{~cm}^{-1}$ and $1602 \mathrm{~cm}^{-1}$ representing $\mathrm{O}-\mathrm{H}$, aliphatic $\mathrm{C}-\mathrm{H}$ and $\mathrm{C}=\mathrm{O}$, respectively, vanished, which indicates that at modest pyrolysis temperatures hydroxyl and $\mathrm{CO}_{2}$ are liberated mainly by direct dehydration and decarbonylation reactions, respectively (Wang et al. 2018) It can be spotted that signals 
at around $1000 \mathrm{~cm}^{-1}$ arrange in the spectra of hemicellulose and cellulose are originated from the hydroxyl and either groups of polysaccharides. The last spectra are different from the spectra of lignin(Cao et al. 2014).

\section{Bio-oil characterization}

321 FTIR analyzes have also designed that the functional groups of bio-oils at different pyrolysis temperatures are quite similar (Fig.5 (b)). Table 3 shows the functional groups and corresponding classification of compounds. The stretching vibration of $\mathrm{OH}(3300-$ $3600 \mathrm{~cm}^{-1}$ ) designates the presence of alcohols and phenols. The absorbance of peaks between 1578 and $1686 \mathrm{~cm}^{-1}$ representing $\mathrm{C}=\mathrm{C}$ stretching vibrations is indicative of alkenes and aromatics. The absorption of aliphatic $\mathrm{CH}_{2}$ at $1420 \mathrm{~cm}^{-1}$ indicates the presence of alkanes or aliphatic hydrocarbon chains in heteroatomic compounds. The absorption bands between 1672 and $1607 \mathrm{~cm}^{-1}$ indicate the presence of carboxylic acids and aldehydes; the three bio-oils obtained at different temperatures represent the same absorption band at $1638 \mathrm{~cm}^{-1}$ with different intensities. The possible presence of aromatic esters is indicated by the absorbance peaks between 657 and $670 \mathrm{~cm}^{-1}$ as well as $\mathrm{C}-\mathrm{O}$ stretch indicates the presence of aromatic (Demiral and Asl 2011). GC-MS analysis was performed to determine the organic compounds of the bio-oils presented in Figure 6. The bio-oil was mainly composed of alcohols, carboxylic acids, phenols, fatty acids, aldehydes, nitrogenous compounds (indoles and pyridines) which is are consequences of the features of the components in the pectin, hemicellulose, cellulose and lignin contained in LPW.

The major detected compounds in the bio-oil sample were n-hexadecanoic acid (palmitic acid) (19.98\%) and (10.74\%); 9-octadecenoic acid (oleic acid) (12.7\%) and 
$300^{\circ} \mathrm{C}$ pyrolytic temperatures in Table 4 . The components of the bio-oil at $500^{\circ} \mathrm{C}$ were similar to the liquid product obtained by Primaz et al., 2018 (2018). The other useful compounds that were found on the bio-oil at $500^{\circ} \mathrm{C}$ were: squalene, $\mathrm{d}$-limonene and $\beta$ -

344 Sitosterol. The components of the bio-oil were similar to the liquid product obtained by 345 other researchers (Kim et al. 2015b; Liu et al. 2017). The most abundant phenols accounted for $16.3 \%$ at the temperature of $400^{\circ} \mathrm{C}$. The existence of phenolic and aromatic compounds in pyrolysis oil were due to the thermal degradation of lignin and was also seen in the FTIR spectral regions of $3300-3600 \mathrm{~cm}^{-1}$ (Bhattacharjee and Biswas 2019).

The major compound found in the bio-oil fraction obtained during pyrolysis at $400^{\circ} \mathrm{C}$ is glycerol $(23.5 \%)$. It is a foremost renewable raw material used essentially in the chemical industry. The prevailing compounds obtained are hydroquinone and 4coumaric acid. The oxygenated compounds correspond to saccharides. The pyrolysis mechanism of hemicelluloses is very similar to that of cellulose, which also starts with the depolymerization of polysaccharide chains to form oligosaccharides, following the cleavage of the xylan chain in the glycosidic linkage and rearrangement of the produced molecules (Liu et al. 2017). The nitrogen-containing heterocyclic compounds in biooils, such as pyridines, are supposed to be derived from protein degradation (Zhou et al. 2010).

\section{Gas characterization}

361 The composition of produced synthesis gas and their corresponding heating value (LHV) are presented in Table 5. Carbon monoxide (CO) was the largest amount of the chemicals in the pyrolytic gas which contributed to about 75.87 wt. $\%$ at $400^{\circ} \mathrm{C}$ but at $500^{\circ} \mathrm{C}$ the concentration of $\mathrm{CO}$ decreased about 59.8 wt. $\%$. The contents of carbon 
dioxide increasingly from $0.12 \mathrm{wt} . \%$ at $300^{\circ} \mathrm{C}$ to $0.72 \mathrm{wt} . \%$ at $500^{\circ} \mathrm{C}$. The $\mathrm{CO}$ and $\mathrm{CO}_{2}$ contents of the gaseous fraction are indicators of the oxygen present in the sample. This oxygen derives from the pyrolytic decomposition of partially oxygenated organic compounds (cellulose, lignin, lipids and carbohydrates). These results are almost like values found in previous studies on pyrolysis of different feedstocks at maximum temperature $500^{\circ} \mathrm{C}$ : for example, Bensidhom et al. (2017)reported for the gas produced from date palm waste pyrolysis an yield of CO ranging from 30 to $55 \mathrm{wt} . \%$ and an yield of $\mathrm{CO}_{2}$ ranging from 0.33 to $0.55 \mathrm{wt} . \%$. The presence in the gaseous mixture of $\mathrm{CH}_{4}$ in significant proportions gives it good fuel properties. The releasing of $\mathrm{CH}_{4}$ can be caused by the cracking of methoxyl-O- $\mathrm{CH}_{3}$, and was mainly focused at low temperatures $(<$ $\left.600{ }^{\circ} \mathrm{C}\right)$. Hemicellulose, cellulose and lignin all contributed to the releasing of $\mathrm{CH} 4$ from biomass pyrolysis, at respectively low, middle and high temperature ranges. The yield of $\mathrm{H}_{2}$ was also very low $(\leq 0.46 \mathrm{wt} . \%)$. In the present experiments, $\mathrm{CO}, \mathrm{CO}_{2}, \mathrm{CH}_{4}$ and LHV decreased when temperature increases from $400^{\circ} \mathrm{C}$ to $500^{\circ} \mathrm{C}$. Furthermore, the lower heating value (LHV) of gas decreased from $12 \mathrm{MJ} / \mathrm{kg}$ to $10 \mathrm{MJ} / \mathrm{kg}$, when the reactor temperature increased from $400^{\circ} \mathrm{C}$ to $500^{\circ} \mathrm{C}$. The large reduction in methane leads to a decrease in the pyrolytic gas LHV of the synthesis gas because methane has the highest calorific value than the other gases (He et al. 2009).

\section{Conclusion}

In this research, dried LPW were converted into biochar, bio-oil and pyrolytic gas using a fixed-bed pyrolysis reactor. The maximum yields of biochar (66.89 wt.\%), bio-oil (16.66 wt.\%) and gas (54.6 wt. \%), were obtained at $300^{\circ} \mathrm{C}, 400^{\circ} \mathrm{C}$ and $500^{\circ} \mathrm{C}$, respectively. The increase of the final temperature was followed by an important increase of the production of non-condensable compounds but resulted in a decrease in 
the biochar yield. The produced bio-oil is composed namely of phenols, acids, terpenes, alcohols and nitrogen compounds. This study has shown that LPW could be processed to obtain bio-oil and biochar, containing active biomolecules with high added-value having potential applications in agriculture, pharmaceutical and nutraceutical industries. Besides produced chars, little ash and high calorific value could be used to replace the most valuable conventional fossil fuels. The present feasability study have to be completed by an economic analysis of the examination of the hole process efficiency taking into consideration all produced economic value products (energy forms, active molecules, potential fertilizer) and in a biorefinery facility approach. The outcomes of this work could be adopted by citrus farmers and agri-food industrials to ensure a sustainable citrus by-products waste management and to provide economic benefits in this economic sector.

\section{Acknowledgements}

This work is co-financed by Young Researcher Programs. Project Ref. 18PJECI-12-05. Thermochemical conversion of citrus co-products and sardine into biofuels rich in active molecules. The authors gratefully acknowledge the Tunisian Ministry of Higher Education and Research for financial support. The authors gratefully acknowledge the revision of the English of the final manuscript by Pr. Benlarbi Maha, Researcher at Clore Laboratory, University of Buckingham, United Kingdom and at Laboratory of Physiopathology, Alimentation and Biomolecules, University of Manouba. 
- Ethical Approval

- Not applicable 


\section{References}

435 Abnisa F, Wan Daud WMA (2014) A review on co-pyrolysis of biomass: An optional technique to obtain a high-grade pyrolysis oil. EAbnisa, F, Wan Daud, WMA, 2014 A Rev co-pyrolysis biomass An optional Tech to obtain a high-grade pyrolysis oil Energy Convers Manag 87, 71-85 https//doi.org/101016/j.enconman201407007nergy Convers Manag 87:71-85. https://doi.org/10.1016/j.enconman.2014.07.007

Aboulkas A, Hammani H, El Achaby M, et al (2017) Valorization of algal waste via pyrolysis in a fixed-bed reactor: Production and characterization of bio-oil and biochar. Bioresour Technol 243:400-408. https://doi.org/10.1016/j.biortech.2017.06.098

Adeniyi AG, Otoikhian KS, Ighalo JO, Mohammed IA (2019) Pyrolysis of Different Fruit Peel Waste Via a Thermodynamic Model. ABUAD J Eng Res Dev 2:16-24

AFNOR French Association for Standardization 2010 (2010) AFNOR French Association for Standardization, 2010. Solid biofuels - AFNOR XP CEN/TS 14774-3: NF EN 14774-3; AFNOR - XP CEN/TS 14775: NF EN 14775

Aguiar L, Márquez-Montesinos F, Gonzalo A, et al (2008) Influence of temperature and particle size on the fixed bed pyrolysis of orange peel residues. J Anal Appl Pyrolysis 83:124-130. https://doi.org/10.1016/j.jaap.2008.06.009

Ahmad Taghizadeh-Alisaraei , Seyyed Hasan Hosseini, Barat Ghobadian AM (2016) Biofuel production from citrus wastes: A feasibility study in Iran. Renew Sustain Energy Rev 69:1100-1112. https://doi.org/10.1016/j.rser.2016.09.102 
Alvarez J, Hooshdaran B, Cortazar M, et al (2018) Valorization of citrus wastes by fast pyrolysis in a conical spouted bed reactor. Fuel 224:111-120. https://doi.org/10.1016/j.fuel.2018.03.028

Anukam AI, Mamphweli SN, Reddy P, Okoh OO (2016) Characterization and the effect of lignocellulosic biomass value addition on gasification efficiency. Energy Explor Exploit 34:865-880. https://doi.org/10.1177/0144598716665010

Arni S Al (2017) Comparison of slow and fast pyrolysis for converting biomass into fuel. Renew Energy 124:197-201. https://doi.org/10.1016/j.renene.2017.04.060

Ben Hassen Trabelsi A, Zaafouri K, Baghdadi W, et al (2018) Second generation biofuels production from waste cooking oil via pyrolysis process. Renew Energy 126:888-896. https://doi.org/10.1016/j.renene.2018.04.002

Bensidhom G, Hassen-trabelsi A Ben, Alper K, et al (2017) Pyrolysis of Date palm waste in a fixed-bed reactor: characterization of pyrolytic products. Bioresour Technol. https://doi.org/10.1016/j.biortech.2017.09.066

Bhattacharjee N, Biswas AB (2019) Pyrolysis of orange bagasse: Comparative study and parametric influence on the product yield and their characterization. J Environ Chem Eng 7:102903. https://doi.org/10.1016/j.jece.2019.102903

Boluda-Aguilar M, García-Vidal L, González-Castañeda F d P, López-Gómez A (2010) Mandarin peel wastes pretreatment with steam explosion for bioethanol production. Bioresour Technol 101:3506-3513. https://doi.org/10.1016/j.biortech.2009.12.063

Boluda-Aguilar M, López-Gómez A (2012) Production of bioethanol by fermentation of 
lemon (Citrus limon L.) peel wastes pretreated with steam explosion. Ind Crop Prod 41:188-197. https://doi.org/10.1016/j.indcrop.2012.04.031

Cao X, Zhong L, Peng X, et al (2014) Comparative study of the pyrolysis of lignocellulose and its major components: Characterization and overall distribution of their biochars and volatiles. Bioresour Technol 155:21-27. https://doi.org/10.1016/j.biortech.2013.12.006

Chiodo V, Urbani F, Zafarana G, et al (2017a) Syngas production by catalytic steam gasification of citrus residues. Int J Hydrogen Energy 42:28048-28055. https://doi.org/10.1016/j.ijhydene.2017.08.085

Chiodo V, Urbani F, Zafarana G, et al (2017b) Syngas production by catalytic steam gasification of citrus residues. Int J Hydrogen Energy 1-8. https://doi.org/10.1016/j.ijhydene.2017.08.085

Demiral I, Asl E (2011) Pyrolysis of grape bagasse : Effect of pyrolysis conditions on the product yields and characterization of the liquid product. Bioresour Technol 102:3946-3951. https://doi.org/10.1016/j.biortech.2010.11.077

Dhyani V, Bhaskar T (2017) A comprehensive review on the pyrolysis of lignocellulosic biomass. Renew Energy 129 part B:695-716. https://doi.org/10.1016/j.renene.2017.04.035

Fernandez A, Saffe A, Pereyra R, et al (2016) Kinetic study of regional agro-industrial wastes pyrolysis using non-isothermal tga analysis. Appl Therm Eng 106:11571164. https://doi.org/10.1016/j.applthermaleng.2016.06.084

Ghanem Romdhane N, Bonazzi C, Kechaou N, Mihoubi NB (2015) Effect of Air- 
500

501

502

503

504

505

506

507

508

509

510

511

512

513

514

515

516

517

518

519

520

521

Drying Temperature on Kinetics of Quality Attributes of Lemon (Citrus limon cv. lunari) Peels. Dry Technol 33:1581-1589. https://doi.org/10.1080/07373937.2015.1012266

GIFruits 2018 GIFruits - Groupement Interprofessionnel des Fruits - Tunisie 2018

He M, Xiao B, Hu Z, et al (2009) Syngas production from catalytic gasification of waste polyethylene : Influence of temperature on gas yield and composition. Int J Hydrogen Energy 34:1342-1348. https://doi.org/10.1016/j.ijhydene.2008.12.023

Kim B-S, Kim Y-M, Jae J, et al (2015a) Pyrolysis and catalytic upgrading of Citrus unshiu peel. Bioresour Technol 194:312-319. https://doi.org/10.1016/j.biortech.2015.07.035

Kim B-SS, Kim Y-MM, Jae J, et al (2015b) Pyrolysis and catalytic upgrading of Citrus unshiu peel. Bioresour Technol 194:312-319. https://doi.org/10.1016/j.biortech.2015.07.035

Liu WJ, Li WW, Jiang H, Yu HQ (2017) Fates of Chemical Elements in Biomass during Its Pyrolysis. Chem Rev 117:6367-6398. https://doi.org/10.1021/acs.chemrev.6b00647

Lopez-Velazquez MA, Santes V, Balmaseda J, Torres-Garcia E (2013) Pyrolysis of orange waste: A thermo-kinetic study. J Anal Appl Pyrolysis 99:170-177. https://doi.org/10.1016/j.jaap.2012.09.016

M'hiri N, Ioannou I, Mihoubi Boudhrioua N, Ghoul M (2015) Effect of different operating conditions on the extraction of phenolic compounds in orange peel. Food Bioprod Process 96:161-170. https://doi.org/10.1016/j.fbp.2015.07.010 
522 Mahato N, Sharma K, Sinha M, et al (2020) Bio-sorbents, industrially important 523 chemicals and novel materials from citrus processing waste as a sustainable and 524 renewable bioresource : A review. J Adv Res 23:61-82. https://doi.org/10.1016/j.jare.2020.01.007

526

527

528

529

530

531

532

Miranda R, Bustos-Martinez D, Blanco CS, et al (2009) Pyrolysis of sweet orange (Citrus sinensis) dry peel. J Anal Appl Pyrolysis 86:245-251. https://doi.org/10.1016/j.jaap.2009.06.001

Morales S, Miranda R, Bustos D, et al (2014) Solar biomass pyrolysis for the production of bio-fuels and chemical commodities. J Anal Appl Pyrolysis 109:6578. https://doi.org/10.1016/j.jaap.2014.07.012

Negro V, Ruggeri B, Fino D (2018) Recovery of Energy from Orange Peels Through Anaerobic Digestion and Pyrolysis Processes after d-Limonene Extraction. Waste and Biomass Valorization 9:1331-1337. https://doi.org/10.1007/s12649-017-9915-

Pathak PD, Mandavgane SA, Kulkarni BD (2017) Fruit peel waste: Characterization and its potential uses. Curr Sci 113:444-454. https://doi.org/10.18520/cs/v113/i03/444-454

Patsalou M, Chrysargyris A, Tzortzakis N, Koutinas M (2020) A biorefinery for conversion of citrus peel waste into essential oils, pectin, fertilizer and succinic acid via different fermentation strategies. Waste Manag 113:469-477. https://doi.org/10.1016/j.wasman.2020.06.020 
Primaz CT, Schena T, Lazzari E, et al (2018) Influence of the temperature in the yield and composition of the bio-oil from the pyrolysis of spent co ff ee grounds : Characterization by comprehensive two dimensional gas chromatography. Fuel 232:572-580. https://doi.org/10.1016/j.fuel.2018.05.097

Sharma K, Mahato N, Lee YR (2018) Extraction, characterization and biological activity of citrus flavonoids. Rev Chem Eng 35:265-284. https://doi.org/10.1515/revce-2017-0027

Siles JA, Vargas F, Gutiérrez MC, et al (2016) Integral valorisation of waste orange peel using combustion, biomethanisation and co-composting technologies. Bioresour Technol 211:173-182. https://doi.org/10.1016/j.biortech.2016.03.056

Siles López QL\& IPT, ToLópez S, Li Q, et al (2010) Biorefinery of waste orange peel. Crit Rev Biotechnol 30:63-69. https://doi.org/10.3109/07388550903425201

Sukumar V, Manieniyan V, Senthilkumar R, Sivaprakasam S (2020) Production of bio oil from sweet lime empty fruit bunch by pyrolysis. Renew Energy 146:309-315. https://doi.org/10.1016/j.renene.2019.06.156

Varma AK, Mondal P (2016) Physicochemical characterization and kinetic study of pine needle for pyrolysis process. J Therm Anal Calorim 124:487-497. https://doi.org/10.1007/s10973-015-5126-7

Volpe M, Panno D, Volpe R, Messineo A (2015) Upgrade of citrus waste as a biofuel via slow pyrolysis. J Anal Appl Pyrolysis 115:66-76. https://doi.org/10.1016/j.jaap.2015.06.015 
Volpe R, Menendez JMB, Reina TR, et al (2017) Evolution of chars during slow pyrolysis of citrus waste. Fuel Process Technol 158:255-263. https://doi.org/10.1016/j.fuproc.2017.01.015

Wang S, Jiang D, Cao B, et al (2018) Bio-char and bio-oil characteristics produced from the interaction of Enteromorpha clathrate volatiles and rice husk bio-char during co-pyrolysis in a sectional pyrolysis furnace: A complementary study. J Anal Appl Pyrolysis 135:219-230. https://doi.org/10.1016/j.jaap.2018.08.030

Wei Y, Li J, Shi D, et al (2017) Resources , Conservation and Recycling Environmental challenges impeding the composting of biodegradable municipal solid waste : A critical review. "Resources, Conserv Recycl 122:51-65. https://doi.org/10.1016/j.resconrec.2017.01.024

Yin C-Y (2011) Prediction of higher heating values of biomass from proximate and ultimate analyses Chun-Yang. Fuel 90:1128-1132. https://doi.org/10.1016/j.fuel.2010.11.031

Zaafouri K, Ben Hassen Trabelsi A, Krichah S, et al (2016) Enhancement of biofuels production by means of co-pyrolysis of Posidonia oceanica (L.) and frying oil wastes: Experimental study and process modeling. Bioresour Technol 207:387398. https://doi.org/10.1016/j.biortech.2016.02.004

Zema DA, Calabrò PS, Folino A, et al (2018) Valorisation of citrus processing waste : A review. Waste Manag 80:252-273. https://doi.org/10.1016/j.wasman.2018.09.024

Zhou D, Zhang L, Zhang S, et al (2010) Hydrothermal Liquefaction of Macroalgae 
Enteromorpha prolifera to Bio-oil. Energy and Fuels 24:4054-4061.

589 https://doi.org/10.1021/ef100151h

590

591 
Figures

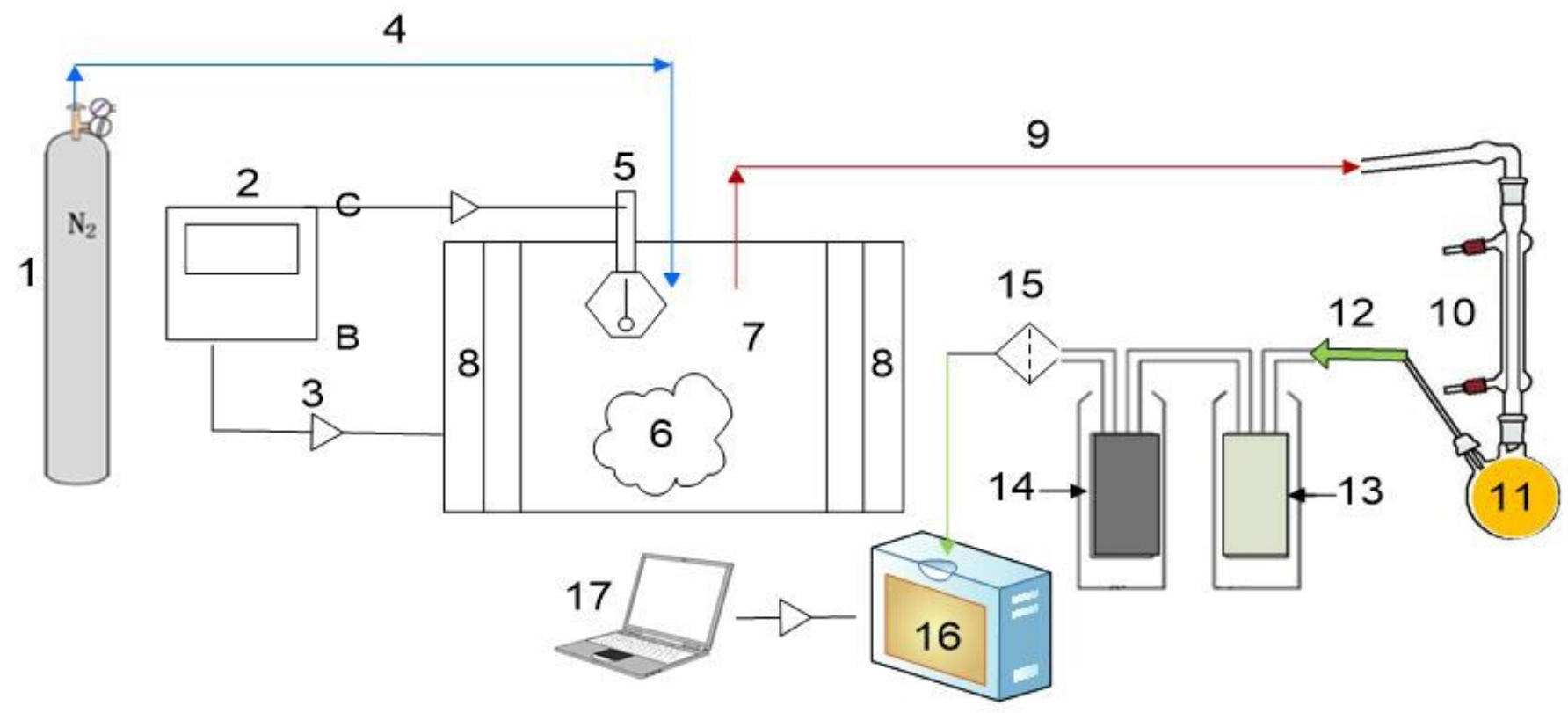

Figure 1

Schematic of pyrolysis system used in LPW (Ben Hassen et al. 2018) 1: N2 gas cylinder; 2: Heating control panel; 3: control transfer; 4: N2 Inlet; 5: Thermocouple; 6: 162 WCO; 7: pyrolysis reactor; 8:

Electrical furnace; 9: Vapors outlet; 10: Condensation system; 11: 163 Liquid fraction ; 12: non condensable gases; 13: Gas purification system ; 14: Activated carbon 164 column ; 15: gas filter ; 16: Gas analyzer ; 17: Laptop for data acquisition. 


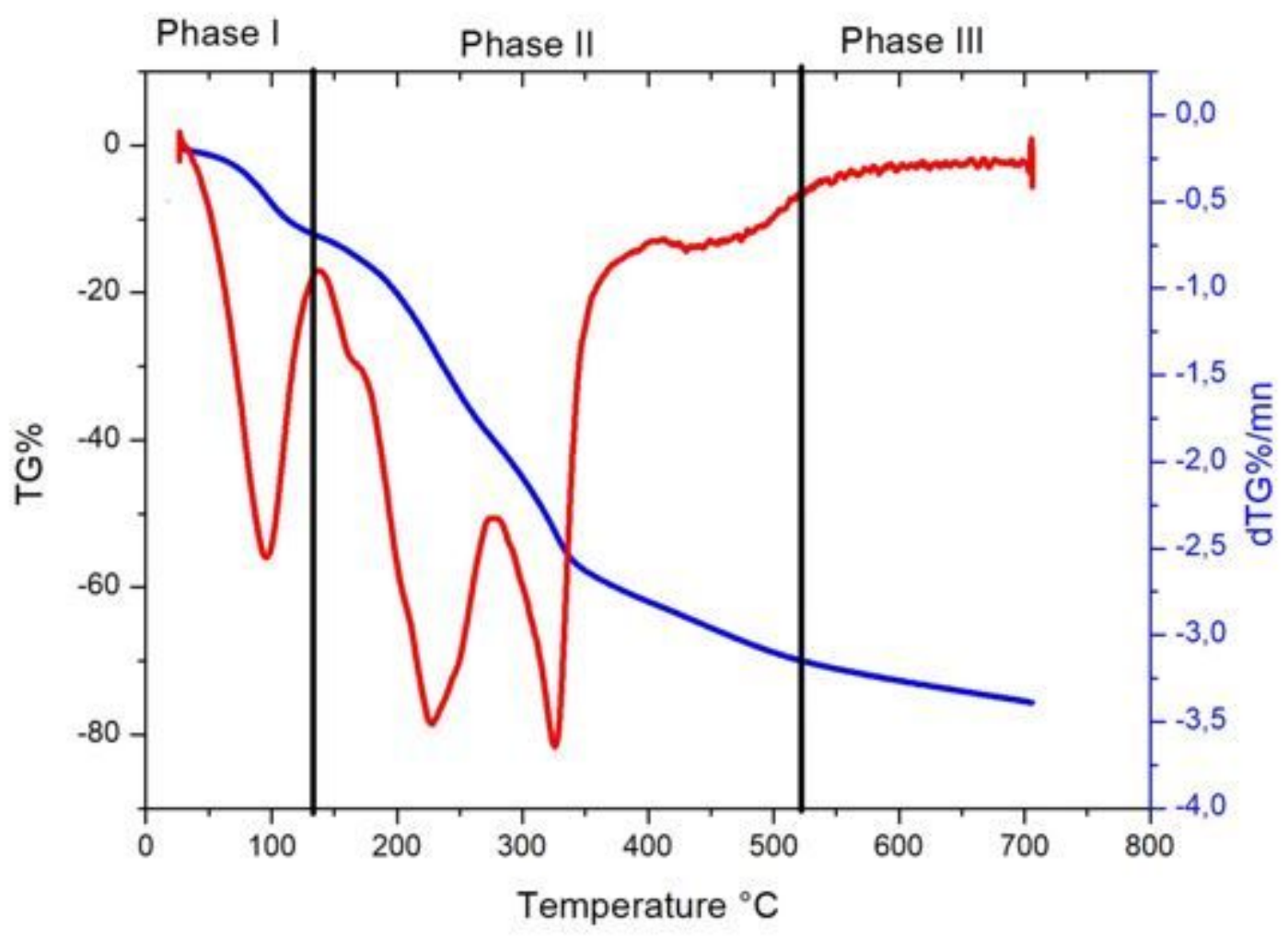

Figure 2

Thermo Gravimetric Analysis of Lemon Peel Waste

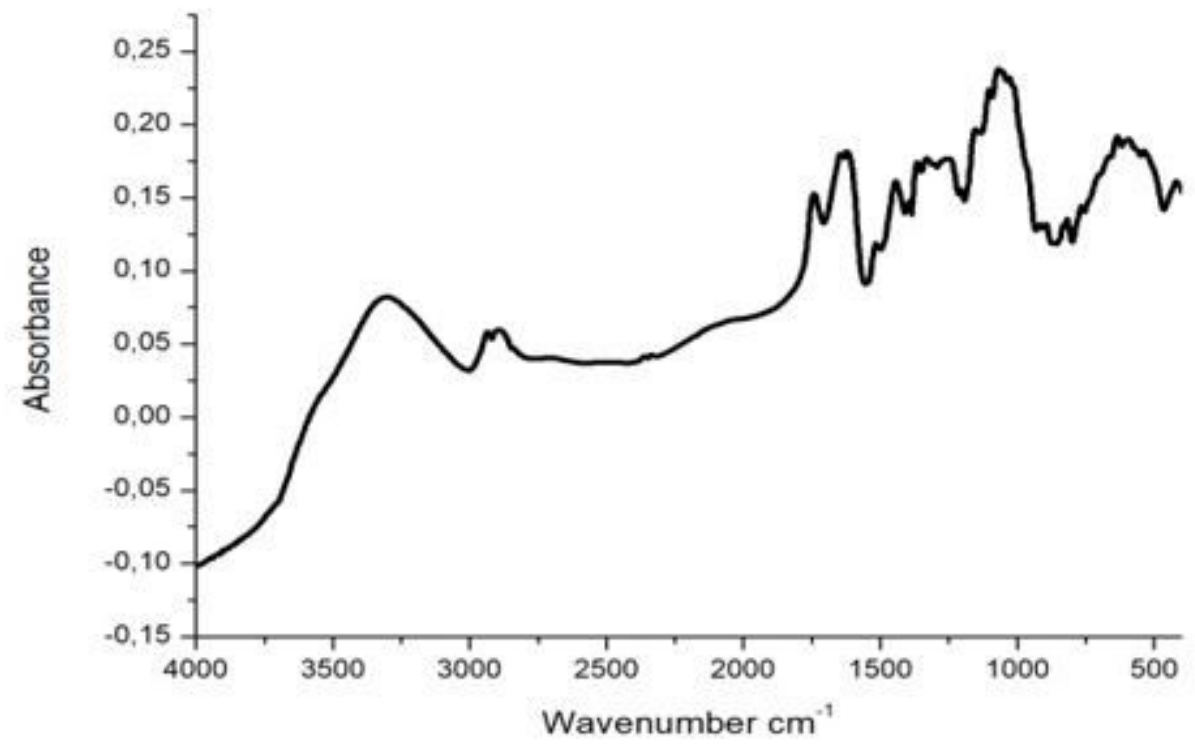

Figure 3 
FTIR spectrum of Lemon Peel Waste

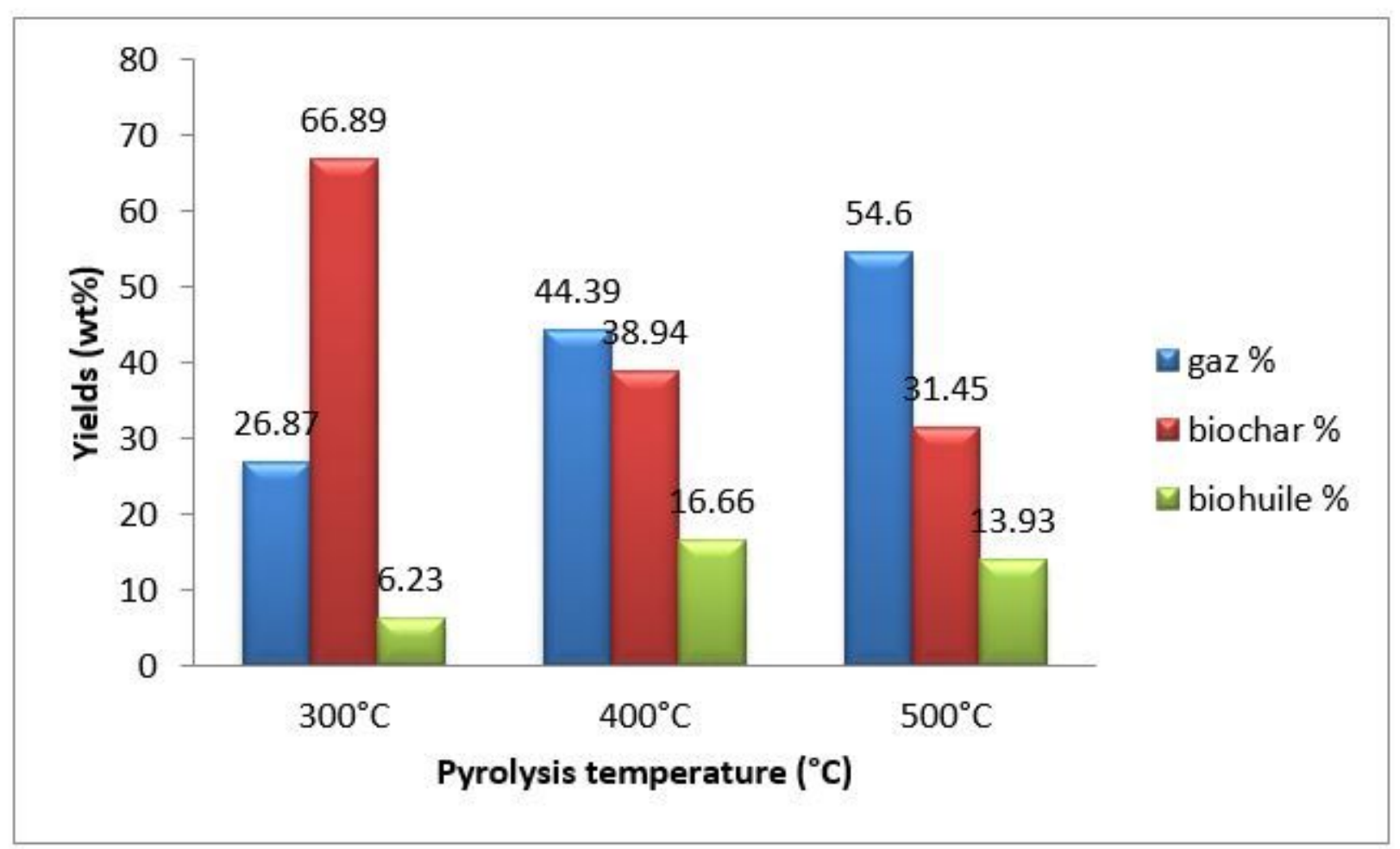

Figure 4

Yields of pyrolysis products obtained at 300,400 and $500^{\circ} \mathrm{C}$ from Lemon Peel Waste at heating rate of $10^{\circ} \mathrm{C} / \mathrm{min}$
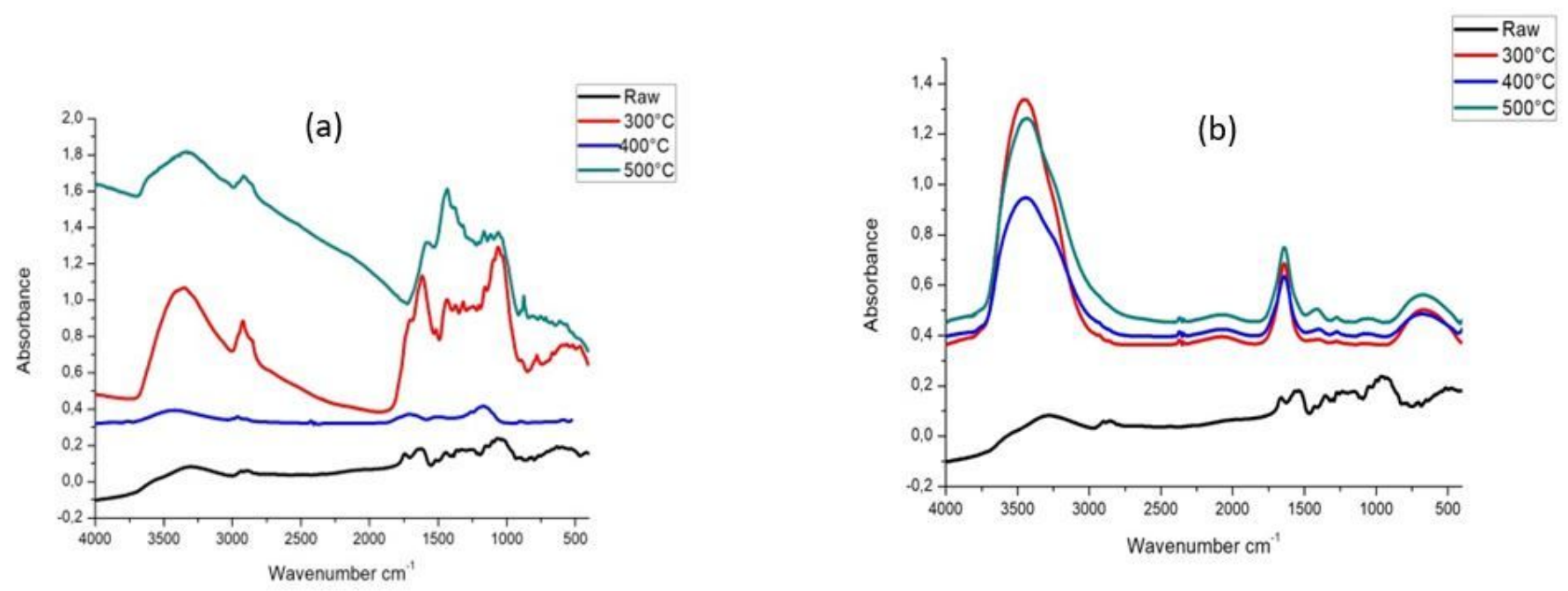

Figure 5 
FTIR spectrums of bio-char (a) and bio-oil (b)

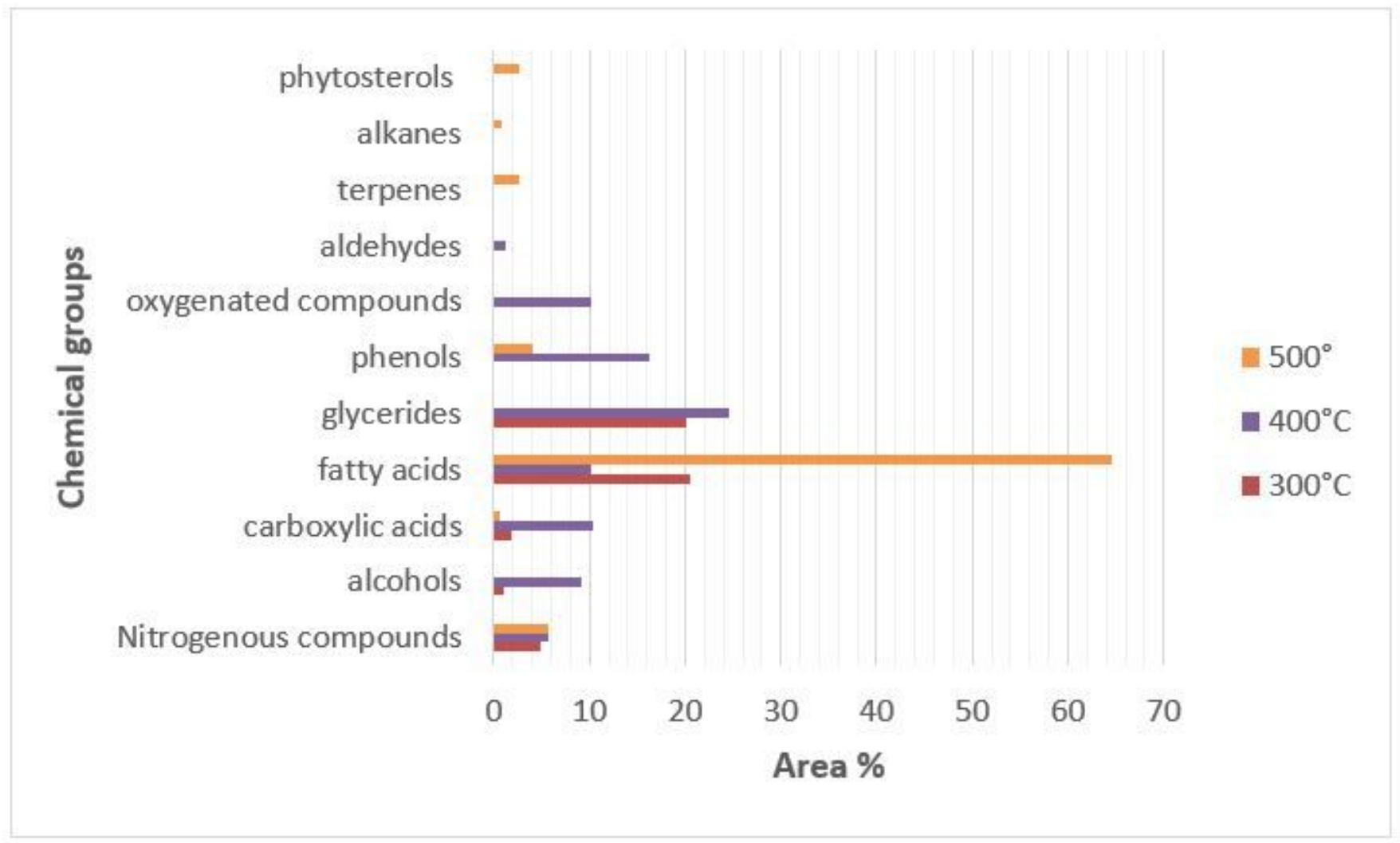

Figure 6

Distribution of organic compounds in bio-oil samples produced under different temperatures 